\title{
La piedra con «cúpulas» del Pla de Forcs (Sant Iscle de Vallalta, Maresme, Barcelona)
}

\author{
Ricard Pascual Guasch
}

En la investigación arqueológica hay temas que, sin duda, padecen una discriminación y si alguien se ocupa de ellos es considerado con cierta prevención, como si se tratase de algo poco serio o fantasioso o incluso esotérico. Uno de ellos es la cuestión de las insculturas, sobre todo cuando éstas presentan su forma más elemental de simples cúpulas o cazoletas excavadas en la piedra.

La descripción de una de estas piedras y unas consideraciones generales sobre las mismas es el tema que hemos escogido para el homenaje al Dr. Ripoll y nos hemos atrevido a ofrecerle algo, tal vez poco académico, porque nos consta que es una mentalidad abierta, con una curiosidad intelectual inagotable y por ello carente de prejuicios sobre determinadas cuestiones.

La piedra que vamos a analizar se halla en la vertiente Sur de la montaña del Montnegre que con sus $758 \mathrm{~m}$. es el punto de mayor altitud de la Sierra Litoral Catalana o Sierra de Marina que se extiende paralela a la costa desde el Norte de Barcelona al río Tordera. En su suave relieve se hallan algunas altiplanicies de extensión reducida, en una de ellas, llamada Pla de Forcs o de Feres, se encuentra la piedra que ahora nos interesa. El terreno está cubierto de bosques de encinas, alcornoques y pinos con frecuentes afloraciones de roca granítica como la de toda la Sierra. En estas afloraciones se encuentran a menudo algunas cavidades semiesféricas de un diámetro que oscila entre los ocho y los $20 \mathrm{~cm}$. y tres o cuatro $\mathrm{cm}$. de profundidad que son lo que llamamos cúpulas. Aparecen aisladas, una en cada roca o formando pequeños con- 


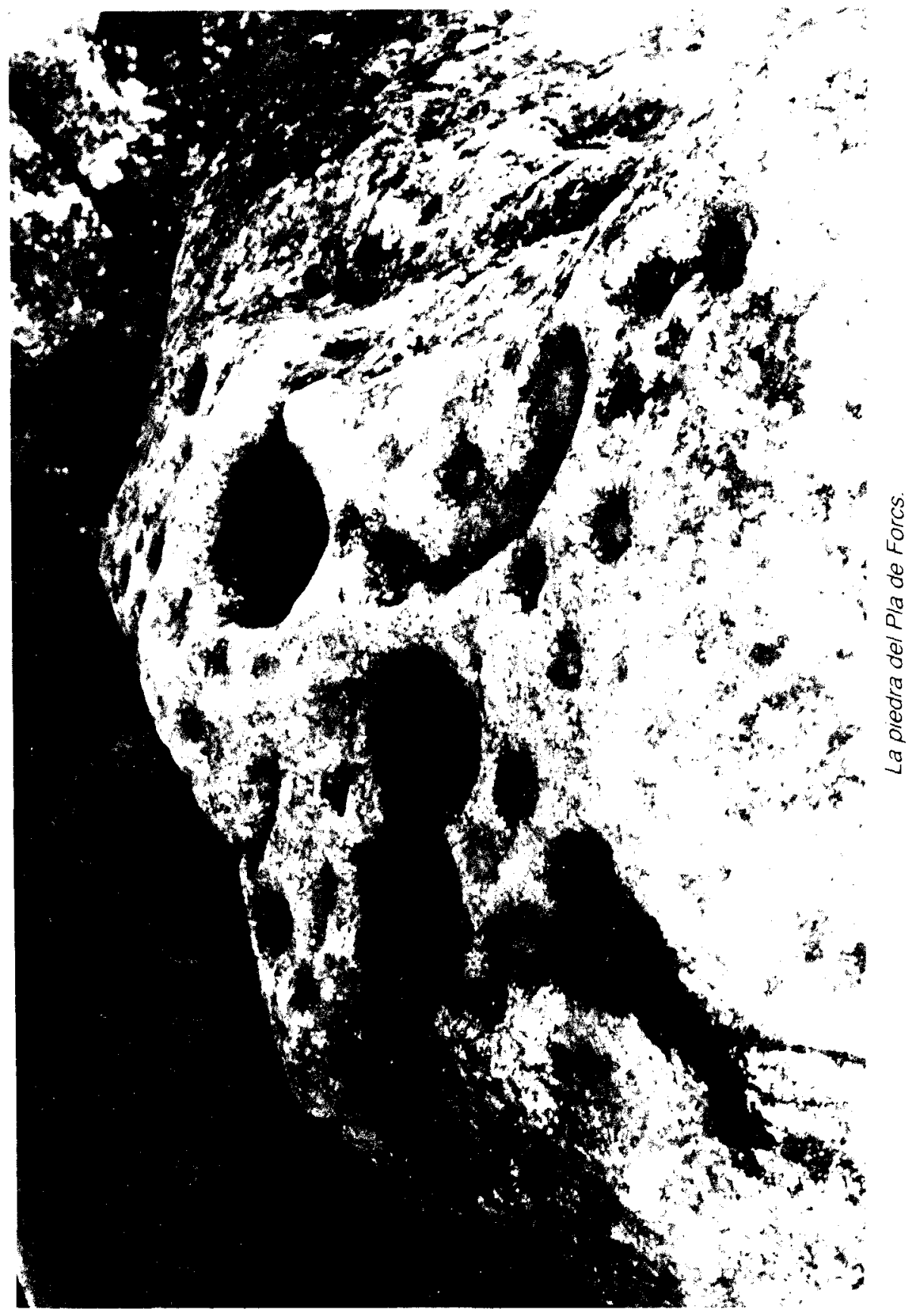




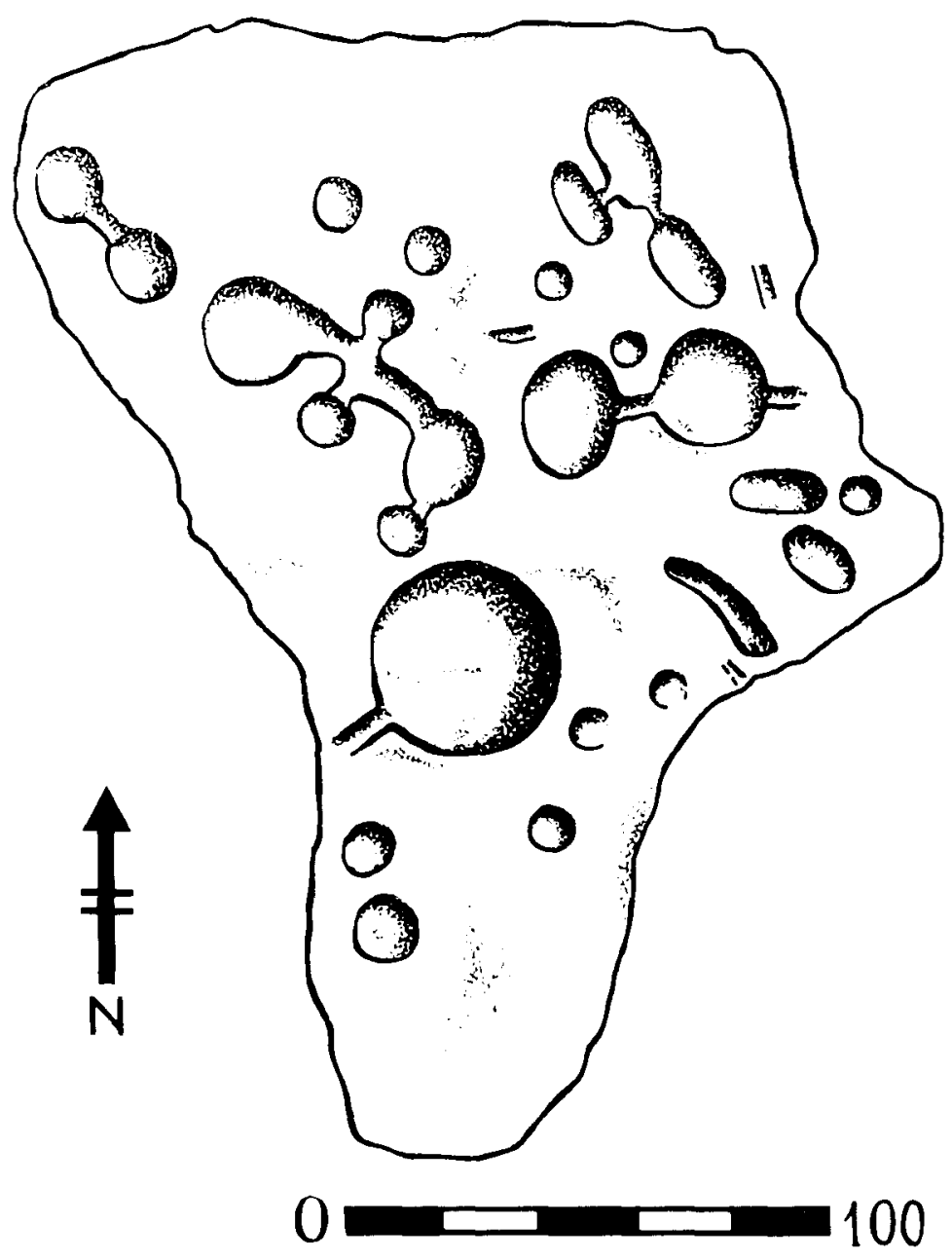

juntos de dos o tres. En el extremo Norte del llano y muy cerca de un viejo camino que sirve de divisoria entre los términos municipales de Vallgorguina y Sant iscle de Vallalta, así como de las comarcas del Vallés y el Maresme y en un terreno de esta última, hay un grupo de tres grandes piedras, una de las cuales presenta más de veinte cúpulas.

Esta roca afecta una planta aproximadamente triangular, con una base de unos $1,80 \mathrm{~m}$. y una altura de $2,30 \mathrm{~m}$. Hacia el centro aparece 
una gran cubeta de $40 \mathrm{~cm}$. de diámetro la cual, excepcionalmente, no es semiesférica sino cilindrica, con una profundidad de $6 \mathrm{~cm}$. Apenas insinuado hay un canal de desagüe que se dirige al borde de la piedra.

Al Norte de esta cubeta y muy cerca de ella se halla un conjunto de cinco cúpulas, dos de unos 18 a $20 \mathrm{~cm}$. y tres de unos $10 \mathrm{~cm}$. unidas entre si por acanaladuras formando un complejo sistema. A su misma altura, hacia el Este, hay dos cúpulas de buen tamaño, $25 \mathrm{~cm}$., ligadas por un canal, la más occidental de las cuales presenta una salida hacia el borde de la piedra.

Al Norte de ellas aparece un conjunto de tres cúpulas elipticas de 10 por $25 \mathrm{~cm}$. aproximadamente, unidas por canales.

En el extremo Noroeste de la piedra hallamos dos cúpulas de $13 \mathrm{~cm}$. unidas formando la figura llamada "haltera" y entre este grupo y el anterior hay cuatro cúpulas irregularmente situadas y no comunicadas.

Por último al Este de la gran cubeta cilíndrica hay un conjunto de tres cúpulas, dos elípticas de 10 por $15 \mathrm{~cm}$. y una circular de ocho $\mathrm{cm}$. Asimismo cercanas a ellas o dispersas al Sur de la gran cubeta hay varias cúpulas pequeñas, entre siete y trece $\mathrm{cm}$., exentas.

En total encontramos 19 cúpulas circulares, cinco elípticas y la gran cubeta cilíndrica, es decir, 25 cavidades aparte los canales.

En las inmediaciones de esta roca, dejando de lado las cúpulas dispersas ya mencionadas, no aparece ningún vestigio que permita atribuirla, ni que sea aproximadamente, a ninguna época o cultura. No obstante el Pla de Forcs está situado en la cabecera del valle de la Riera de Vallgorguina y en él existen algunos elementos que tal vez puedan relacionarse con nuestra piedra: el dolmen de Pedra Gentil, reconstruido y quiza desplazado de su punto original (López Puigbó, en prensa) y el yacimiento del bronce antiguo del Rocar, del que sólo se conocen unos pocos fragmentos cerámicos, pero suficientemente evidentes. Asimismo, está en el valle, aunque en su límite y muy alejado, el poblado prerromano del Puig Castell (Pascual y Barberà 1964, 233-245).

Las piedras con cúpulas son frecuentes en el Rosellón y en el Norte de Italia, algunas han sido estudiadas por Abelanet que las considera de la época del Bronce y ofrece una hipótesis sobre su función que más adelante comentaremos (Abelanet 1986, $161 \mathrm{sig}$ ). Asimismo, se conocen en Tracia, donde existen algunos importantes conjuntos (Triadaphylos, 1985, 128-491). En España, sabemos de varios puntos en que han sido señaladas, pero raramente se les ha prestado atención. Una excepción es el conjunto localizado en Maldà (Urgell) en el que la cúpulas y las 
acanaladuras aparecen en sincronía con unas sepulturas talladas en la roca y que se consideran medievales. Miró, el autor del hallazgo, formula asimismo su hipótesis sobre la que también volveremos (Miró, 1979. 11-14).

Muy interesante es la presencia de cúpulas en construciones megalíticas. Las conocemos en algunos dólmenes de Cataluña, donde a menudo aparecen en la losa de cubierta lo cual obliga a suponerlas de época posterior al monumento, puesto que éste originariamente estaba cubierto por un túmulo de tierra. No obstante, en ocasiones, las cúpulas se hallan en los ortostatos que forman la cámara o el corredor por lo que han de ser contemporáneos o anteriores al megalito. Es decir, en este caso hay que suponer que piedras que tenian cúpulas fueron reutilizadas para la construcción del dolmen.

También, se conocen cubiertas de dolmen con cúpulas, a menudo unidas por acanaladuras formando complicados conjuntos, en Palestina, donde además y en evidente conexión con los megalitos se hallan piedras cubiertas de cúpulas (Stekelis, 1960-61, 49-128). La presencia de cúpulas en piedras más o menos inmediatas a los dólmenes, parece que también se da en Cataluña, pero es un hecho que nunca se ha tenido muy en cuenta (Esteva, 1965, 41-59).

Para este fenómeno cultural de las cúpulas se poseen pocos y contradictorios datos cronológicos. Como se ha dicho, a menudo aparecen en relación con megalitos, pero su contemporaneidad es difícilmente comprobable y en el caso ciertamente excepcional de Maldà se situan en la Edad Media. Evidentemente con semejantes elementos no puede arriesgarse ninguna hipótesis, hay que esperar que este tipo de manifestaciones sean más estudiadas y se posean más datos; con todo no creemos que deba rechazarse, sin más, una posible pervivencia multisecular.

Si su situación en el tiempo resulta incierta, más incierto aún es su significado o su finalidad. No obstante, de su simple observación se desprende su relación con algun elemento líquido y de su situación: dólmenes, tumbas, alguna relación con la muerte.

Las hipótesis propuestas por Abelanet y Miró, como es natural se apoyan en estos conceptos: líquido o agua y muerte o culto a los muertos. El primero, expresándola de forma simbólica y el segundo de manera mucho más directa.

Al igual que en la roca del Pla de Forcs, en muchos otros lugares se ha observado que las cúpulas están dispuestas alrededor de una cubeta de mayor tamaño. Esto ha llevado a Abelanet a denominar el sistema como en forma de "Kernos". 
El «kernos" es un vaso que esencialmente se compone de una cavidad central de cierto tamaño y una serie de pequeños recipientes kotiliskoi situados a su alrededor. La forma general del vaso y el número de pequeños recipientes es indiferente, con tal de que reuna estas dos características se considera un "kernos".

Ciertamente la disposición de algunos conjuntos de cúpulas y la morfología de este vaso presentan un cierto paralelo y si analizamos, aunque sea superficialmente, la difusión geográfica y la función de los «kernoi» su relación parece acentuarse.

«Kernoi» cerámicos han aparecido en un área que prácticamente comprende todo el Mediterráneo. Beltrán señala su presencia en Asia Menor, Creta, Chipre, Egipto, Siria, etc. Asimismo se han hallado en España: en Cabezo de Monleón (Caspe), Cortes de Navarra y Empúries, siempre en niveles pre-ibéricos o hallstáticos y hechos en cerámica indigena (Beltrán, 1959, 144-148). A ellos hay que añadir uno en cerámica barnizada de negro aparecido posteriormente en el pecio de El Sec, en Mallorca, fechado a finales del siglo Iv ante de J.C. (Arribas, Trias, Cerdà y de Hoz, 1987, 367-368). Pero este vaso es más frecuente en Eleusis, cerca de Atenas, donde existió el Santuario de Demeter, conocido por sus célebre misterios.

Según Ateneo de Naucratis, en los pequeños recipientes se depositaban ofrendas de miel, aceite, vino, leche, trigo, cebada, etc. y en la cavidad central un pastel de frutas. Unas muchachas se lo ponian en la cabeza y tomaban parte en una procesión en honor de Demeter, en el Santuario de Eleusis (Ateneo XI, 476f y 478a).

El mito de Demeter es muy antiguo, sin duda de origen prehistórico. Los mitógrafos discuten si procede del centro de Europa y fue llevado a Grecia por los pueblos que la invadieron en el segundo milenio antes de J.C., si tiene un remoto origen oriental, o si procede de la civilización minoica de Creta o si de forma más amplia, tiene su origen en una llamada "religión mediterránea» que en tiempos eneolíticos abarcó toda la cuenca de este mar.

Demeter en principio era una diosa agraria y al desdoblarse en su hija Perséfone adquirió el simbolismo del ciclo vegetal, con su muerte en otoño y su renacimiento en primavera. Por ello son las diosas del eterno renacer y extrapolando este atributo a la vida humana adquieren un caracter escatológico como patronas de la inmortalidad.

La gran difusión y a menudo antigüedad de los "Kernoi" cerámicos permite suponer la existencia de una diosa prehistórica de la agricultura, 
la fertilidad y la vida de ultratumba, a la cual en una etapa remota se le rindió culto en una especie de altares que serían las rocas con cúpulas, el uso de las cuales en el ámbito rural pudo tener una larga pervivencia.

La hipótesis expuesta es más o menos la formulada por Abelanet, en cuanto a la de Miró, el título de su trabajo la sintetiza suficientemente: "sepulcros purificados por las aguas". La relación de cúpulas, canales y tumbas parece clara en Maldà y el autor refuerza su suposición con una cita de Tertuliano (Tertuliano, De Bapt. III, 5) en la que se enaltece la virtud purificadora del agua. Pero la ilustración del sepulcro por medio del agua es un concepto muy anterior al cristianismo.

Efectivamente, en una época muy antigua y en Grecia, encontramos unos notable paralelos. En el siglo $v$ antes de J.C. Sófocles en su tragedia Electra menciona el "agua que purifica" como ofrenda a una tumba, la de Agamenon (Sófacles, Elc, 434) y no en el momento del entierro, sino como un rito en su memoria, y un compilador tardío ya citado, Ateneo, describe el ritual: "se vierte agua y perfumes al lado de la tumba, diciendo: aquí tienes con que lavarte, tu que lo necesitas y lo mereces" (Ateneo, IX, 410 a).

Enlaza con este concepto el uso que en Atenas se hizo del vaso llamado "loutroforos". Es una especie de jarra de buen tamaño, cuerpo ovoidal, largo cuello y dos asas, decorado con figuras negras o rojas según la época, destinado a contener el agua para el baño de la novia la víspera de su boda y también para transportar la usada para lavar a los difuntos. Asimismo y teniendo en cuenta lo que simbolizaba, era colocado sobre la tumba de aquellos que habian muerto ante de casarse, probablemente como ofrenda de agua lustral. Demóstenes, como sinónimo del fallecimiento antes del matrimonio de su personaje, dice que en su tumba hay un «loutroforos" (Demóstenes, Cont. Leoc. 18 y 30).

Como un vaso cerámico abandonado sobre un sepulcro tiene pocas posibilidades de duración, pronto se hicieron de mármol en escultura de bulto y con el tiempo en una placa en relieve. En el cementerio del Cerámico en Atenas, se han hallado restos del vaso y esculturas y estelas con su representación en relieve.

Algunas interpretaciones ochocentistas del fenómeno de las piedras con cúpulas querian ver en ellas una especie de escritura rudimentaria, el llamado alfabeto ógmico (Carreras y Candi 1918, vol. I, $773 \mathrm{sig}$ ). y algunos investigadores posteriores han creido encontrar representaciones de constelaciones, cosa que sólo es posible en los casos en que las cúpulas no son muchas y aun añadiéndole una cierta dosis de fantasía. 
A pesar de que como se ha dicho, su relación con el agua y con la muerte parece bastante clara, no hay que rechazar que sean una simple manifestación de litolatría, la cual está en la base de las religiones más arcaicas y tiene una sobrevivencia extraordinaria.

Dejando aparte el culto a los betylos, de claro origen oriental, pero con una cierta difusión en el Mediterráneo, probablemente por la influencia púnica, en un ambiente plenamente latino encontramos a Tíbulo que a finales del siglo I a. de J.C. atestigua la veneración a ciertas piedras situadas en las encrucijadas (Tibulo, I, 1,11) y Apuleyo, en el siglo II de la Era, nos habla del respeto religioso que le merecen algunas piedras, que untadas de aceite, encuentra por el campo (Apuleyo, Florid, I, 4). Curiosamente, la ofrenda de aceite ya la encontramos en el Génesis, cuando Jacob derrama aceite sobre la piedra que le ha servido de almohada la noche en que ha tenido un sueño profético (Génesis XXVII, 18). La pervivencia del culto a las piedras es larguisima; en el Concilio de Toledo del año 693, o sea unos quinientos años despues de Apuleyo, los obispos de toda España allí reunidos dictan un canon para reprimirlo, prueba evidente de que seguía practicándose (FHA XVI, 364 sig.).

Desde luego todo lo antedicho no son más que elocubraciones hipotéticas y la verdad es que poca cosa se sabe sobre esta manifestación cultural. El camino deseable a seguir es el normal y corriente en toda investigación de este tipo. Habria que conocer la mayor cantidad posible de piedras con cúpulas, dibujarlas, fotografiarlas, estudiar el entorno, establecer comparaciones y sumar datos, con ello este fenómeno que por ahora parece fuera de la ciencia llegaria a ser un conocimiento normalizado.

Terminado este trabajo nos llega un libro de muy reciente edición: Rebullida Conesa Amador, Astronomia y religión en el Neolítico-Bronce, Terrassa 1988. En él se da notícia de varios conjuntos de cúpulas en Cataluña y en el Bajo Aragón. Se cree hallar en ellos un sentido astronómico y calendárico basado en minuciosas observaciones del sol y la luna. De momento parece prudente suspender el juicio sobre esta hipótesis. 


\section{BIBLIOGRAFÍA}

Abelanet, Jean, 1986: Signes sans paroles. París, pág. 161 y sig.

Arribas, A.; Trias, M.G.; CerddA, D. y DE Hoz, J., 1987: El barco de El Sec, Mallorca, pág. 367, 368.

Beltrán, Antonio, 1959: "Un nuevo Kernos del oppidum hallstático del

Cabezo de Monleón (Caspe)", en VI Congreso Nacional de Arqueología, Oviedo, pág. 144 a 148.

CARRERAS i CANDI, Francesc, 1918: Geografia general de Catalunya, Barcelona. Vol. I, pág. 773 y sig.

Esteva Cruañas, Luis, 1965: "Técnica megalítica gerundense", en Arquitectura megalítica Catalano-Balear, Barcelona, págs. 41 a 49.

LÓPEz PuigBo, Jaume: Les bruixes de Vallgorguina i el Dolmen de “Pedra Gentil” (en prensa).

Miró i RosinaCH, Josep María, 1979; "Sis sepulcres purificats per les aigües", en Catalunya Comtal 2, Barcelona.

PASCUAL, Ricardo, y BARBERÁ, José, 1964-65: «El yacimiento prerromano de Puig Castell (Vallgorguina) Barcelona", en Ampurias XXVI-XXVII, Barcelona, págs. 233 a 245.

STEKELIS, M., 1960-61: "La necrópolis megalítica de Ala-Safat, Transjordania", en Ampurias XXII-XXIII, Barcelona, págs 49 a 128.

TrIANDAPHYLLOS, Diamandis, 1985: "Les sanctuaires en plein air dans la region des cicones», en Thracia Pontica III, Sozopol, págs. 128-491. 